\title{
OBSERVATIONS ON SEISMIC WAVES REFLECTED AT THE CORE BOUNDARY OF THE EARTH*
}

\author{
By Samuel T. Martner
}

\section{ABSTRACT}

WAves reflected from the outer boundary of the core of the earth often record trace amplitudes that appear excessive. A comparison of the observed displacements of these phases and the direct body waves is presented. Observational data seem to confirm the idea that the displacement ratios of the longitudinal waves reflected at the core to the longitudinal direct waves is larger than the presently recognized theory indicates. A discussion is included of some possible causes for this difference, but reasonable changes in accepted assumptions fail to explain the entire discrepancy.

\section{INTRODUCTION}

Theoretical investigations of energy transference by seismic waves have been published by many authors; physical measurements of seismic-wave amplitudes and energies, however, have previously been reported only for direct body waves, surface waves, and waves reflected from the surface or crustal layers of the earth [12]. $\dagger$ This paper deals with observed phenomena concerning the energy of seismic waves reflected at the core of the earth. It will be largely restricted to quantitative measurements made during the course of recent research and to some of the resulting implications.

Before the observational data are examined, published theoretical considerations will be presented; not comprehensively, but as a résumé of certain factors relevant to later discussion.

The amplitude of a seismic wave at any point can be ascertained by applying a theory originated by Zoeppritz [20] and represented by the following formula.

where:

$$
A_{e}=C T f \sqrt{\frac{\sin i_{s}}{\cos \Delta \cos i_{o}} \frac{d i_{o}}{d \Delta} e^{-\int k d D}}
$$

$A_{\varepsilon}=$ incident amplitude

$C=$ constant depending on the energy at the focus of the earthquake and the type of wave leaving the focus

$T=$ period of the seismic wave

$f=$ square root of the product of the ratios of transmitted or reflected energy at each discontinuity along the path of the ray

$e^{-\int k d D}=$ absorption along the ray path $D$ where the absorption factor is $k$

$\Delta=$ epicentral distance in degrees of are

$i_{s}=$ angle of incidence of the ray at the surface

$i_{o}=$ angle of incidence of the ray at the recording point.

(For details see Gutenberg [8].)

* Condensed from a thesis submitted in partial fulfillment of the requirements for the degree of Doctor of Philosophy at the California Institute of Technology, Pasadena, California, Manuscript received for publication May 10, 1949.

$\dagger$ Numbers in square brackets refer to contributions listed at the end of this paper. 
To find the displacement of the ground at any point on the earth's surface, the incident amplitude $A_{e}$ must be multiplied by the ratios of the three components of ground displacement $u, v$ (horizontal), or $w$ (vertical) to the incident amplitude $A_{e}$ :

$$
u=A_{e}\left(u / A_{e}\right) ; \quad v=A_{e}\left(v / A_{e}\right) ; \quad w=A_{e}\left(w / A_{e}\right) .
$$

Values of $u / A_{e}, v / A_{e}$, and $w / A_{e}$ have been determined assuming various values of Poisson's ratio at the surface (see [20], [7], [15], and [11]). Throughout the present paper Poisson's ratio of 0.250 will be employed. Reasonable variations in this value will change the ratios in formula (2) no more than 10 per cent.

The variables in equations (1) and (2) have been discussed by Gutenberg [11 and 12]. The absorption factor is relatively small. Gutenberg [12] found $k=0.00012 \mathrm{per} \mathrm{km}$. for the longitudinal waves. Using this value and assuming it to be constant along the entire ray path, and also keeping in mind that the largest difference in the path lengths of the direct waves and the waves reflected from the core is at zero epicentral distance, one finds 0.7 as the maximum value of the absorption term in the amplitude ratio of $\mathrm{PcP} / \mathrm{P}$ or $\mathrm{ScS} / \mathrm{S}$. The amplitude ratio of $\mathrm{PcP} / \mathrm{P}$ will be, therefore, reduced by at most 30 per cent by considering absorption (in lieu of disregarding it). This percentage is theoretically decreased as the epicentral distance is increased; until, at a distance of $103^{\circ}, \mathrm{P}$ grazes the core, and the absorption of both $\mathrm{P}$ and $\mathrm{PcP}$ is theoretically equal. The factor $f$ in equation (1) has been thoroughly discussed by Knott [16], Zoeppritz [19], and Blut [1]. Certain assumptions have been made by all three: (1) elastic processes only are considered and the body forces have been neglected, (2) plane waves have been assumed, and (3) the following boundary conditions must be satisfied at the reflecting or refracting discontinuity: (a) equality of the sums of the normal displacements on the two sides of the discontinuity, $(b)$ equality of the sums of the tangential displacements on the two sides of the discontinuity, $(c)$ equality of the sums of the normal stresses across the discontinuity, and $(d)$ equality of the sums of the tangential stresses across the discontinuity.

Numerical computations for $A_{e}, u, v$, and $w$ as shown in formulas (1) and (2) have been presented by Dana [6] for P, SV, SH, PcP, ScS, PcS, ScP, and many other phases. His calculations are all based on the following assumptions.

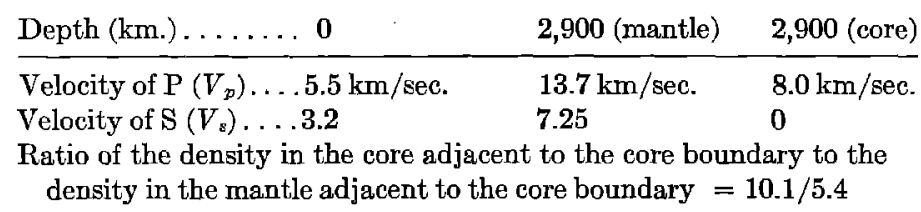

In his calculations the constant $C$ is taken to be equal to $\pi$ and the period $T$ is taken as unity; absorption is neglected. 
Dana also computed the ratios of $u$, $v$, and $w$ for $\mathrm{PcP} / \mathrm{P}, \mathrm{PcS} / \mathrm{P}, \mathrm{ScS}(\mathrm{SV}) / \mathrm{SV}$, $\mathrm{SeS}(\mathrm{SH}) / \mathrm{SH}, \mathrm{SeS}(\mathrm{SH}) / \mathrm{SV}, \mathrm{ScP} / \mathrm{SV}$, and other combinations. As $C$ is constant, at least for the same type of wave (longitudinal or transverse) and the same earthquake if the energy is assumed to be propagated equally in all directions from the focus, this factor cancels in deriving these ratios.

Dana's assumption that the period is 1 sec. gives the same results as though the ratio $u / T$ (or $v / T$ or $w / T$ ) had been computed; therefore, it is necessary to reduce observations to ratios of $u / T, v / T$, or $w / T$.

\section{Methods Used in the Present Study}

The intention of the present study is to compare from the seismograms of teleseisms $u$ (or $v$ or $w$ ) $/ T$ (displacement/period) of phases reflected at the core with the corresponding longitudinal or transverse direct wave. The ratio $u$ (or $v$ or $w$ ) $/ T$ varies directly as the square roots of the energy components.

Seismograms of twenty-eight large earthquakes (4 in Alaska, 4 in Mexico, 3 in Central America, 2 in the Caribbean, 5 in South America, 1 in the Fiji Islands, 2 in New Hebrides, 1 in Japan, 1 in the Kurile Islands, 3 in the Kamchatka peninsula, and 2 in the Atlantic Ocean) recorded by instruments in routine operation at Pasadena, California, were investigated. Shocks were selected with epicentral distances between $20^{\circ}$ and $90^{\circ}$, with magnitudes (on Richter's magnitude scale [18]) of 7.0 or more, with shallow focal depth (in general 10 to $30 \mathrm{~km}$.) occurring in the years 1940 to 1945 , inclusive. Earthquakes with focal depths up to $60 \mathrm{~km}$. were used where shallower shocks were unavailable.

The origin times, locations, and magnitudes of many of these shocks have been published by Gutenberg and Richter [14]; unpublished files of Dr. B. Gutenberg supplied these items for the others.

Trace amplitudes and trace periods of $\mathrm{P}, \mathrm{PcP}, \mathrm{PcS}$ (or $\mathrm{ScP}$ ), $\mathrm{S}$, and $\mathrm{ScS}$ were measured to the closest $0.1 \mathrm{~mm}$. where possible. The trace period is here defined as the time between successive troughs or peaks or the time between alternate crossings of the "zero" line. The maximum accuracy of period measurement is about 0.2 sec. if the period is not too long. Some variation is usually noticed among the oscillations in the same wave train. Maximum amplitudes were measured to the closest $0.1 \mathrm{~mm}$.

From these measurements and specially prepared frequency response curves, the quantity $K A_{d} / T$ ( $A_{d}=$ component of the ground displacement in the free direction of the instrument, $T=$ period of the ground motion, and $K=$ constant for a given instrument and earthquake) was obtained for each phase. If $K A_{d} / T$ for $\mathrm{PcP}$ is divided by $K A_{d} / T$ for $\mathrm{P}$ for the same shock and same instrument, the displacement/period ratio of $\mathrm{PcP} / \mathrm{P}$ is obtained; similarly for other pairs of phases. 
In general, it was assumed that the dominating period carried the predominant energy. However, where more than one pronounced period was registered, several periods and their respective amplitudes were measured; and the set of values corresponding to the greatest energy was used in subsequent calculations.

Examples of results thus obtained are shown in figures 1 to 5. Theoretical ratios are from Dana [6]. As stated previously, the $u$ (or $w$ ) of Dana corresponds to the $u / T$ (or $w / T$ ) of this report.

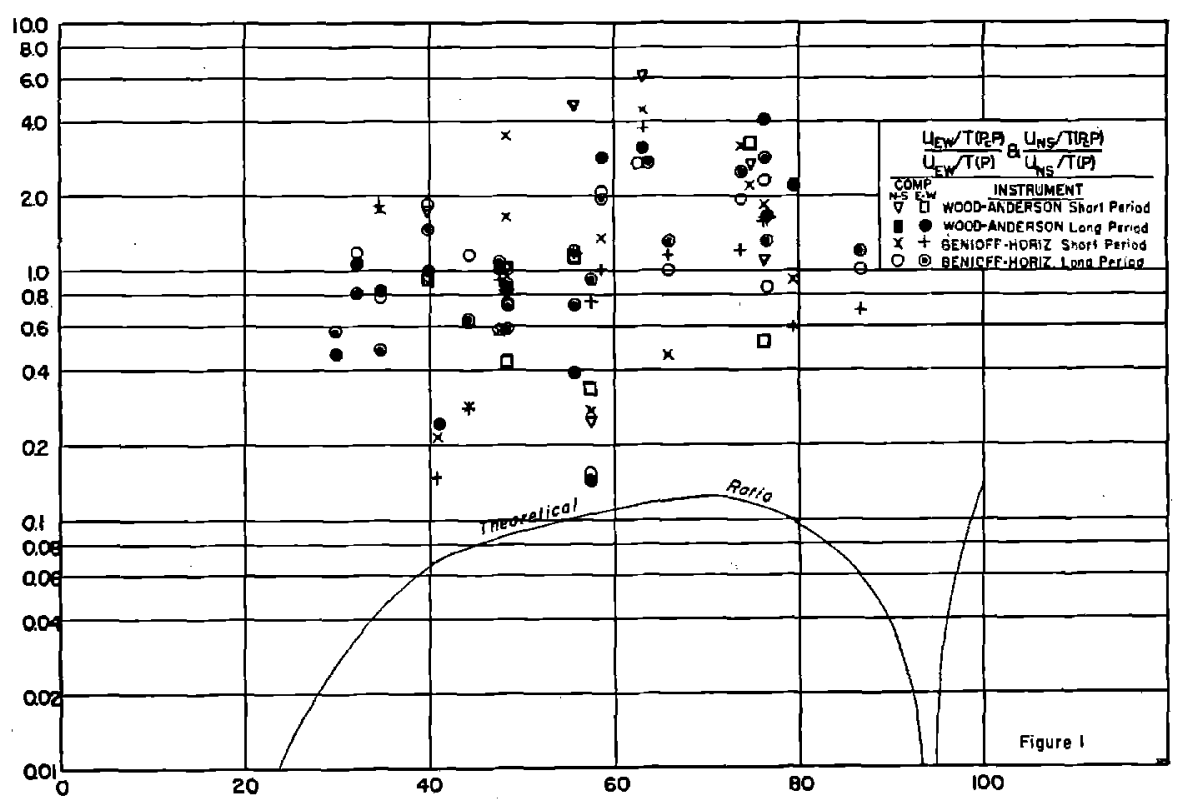

Fig. 1. Observed horizontal displacement/period ratios of $\mathrm{PcP} / \mathrm{P}$.

\section{Discussion of Results}

The data show the wide scatter that is expected. This may be partly due to the assumption that energy is propagated equally in all directions from the focus. The tectonic factors involved make this assumption improbable. However, it seems reasonable to assume that the effect is of a random nature and does not invalidate the use of a statistical mean curve.

Another cause of scatter is the group of assumptions made with regard to the instrumentation and seismogram interpretation. In general, these assumptions account for a deviation of the displacement/period ratios of not more than a factor of 2 or 3 above or below the mean values. This factor is considerably decreased where phases with nearly the same period are being evaluated. 


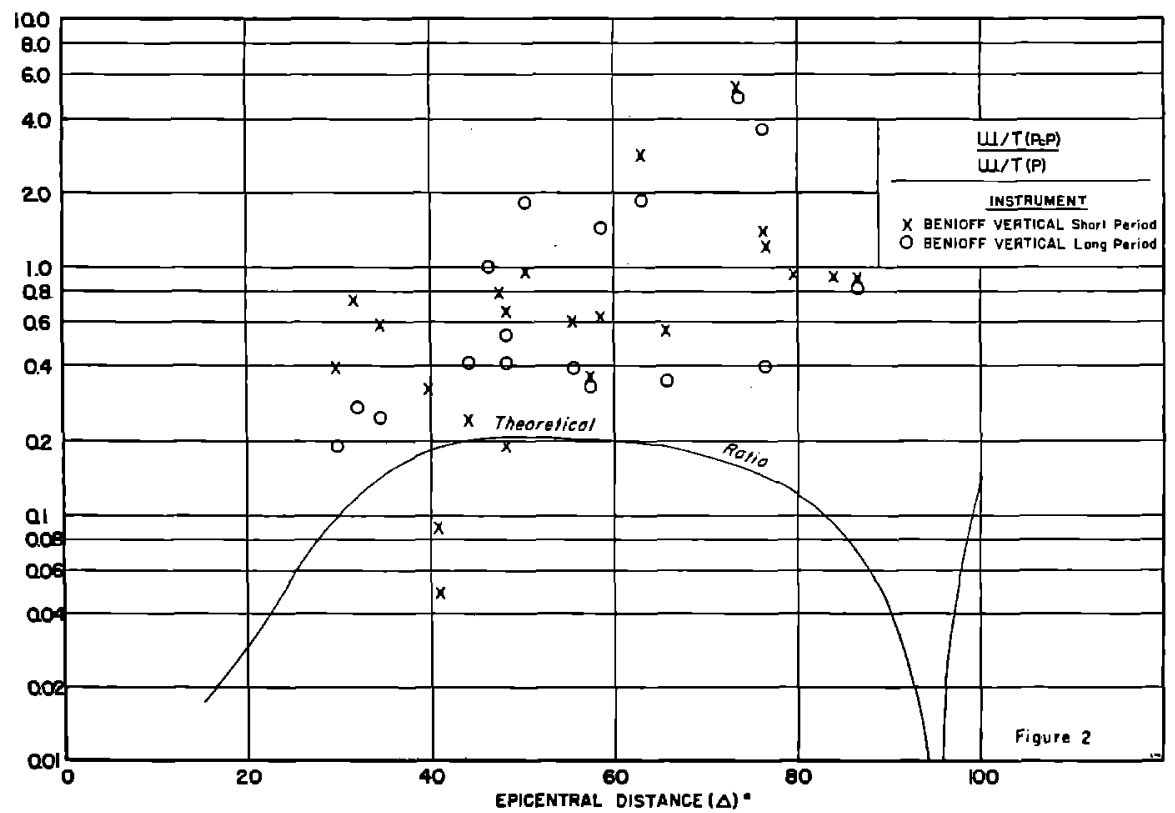

Fig. 2. Observed vertical displacement/period ratios of $\mathrm{PcP} / \mathrm{P}$.

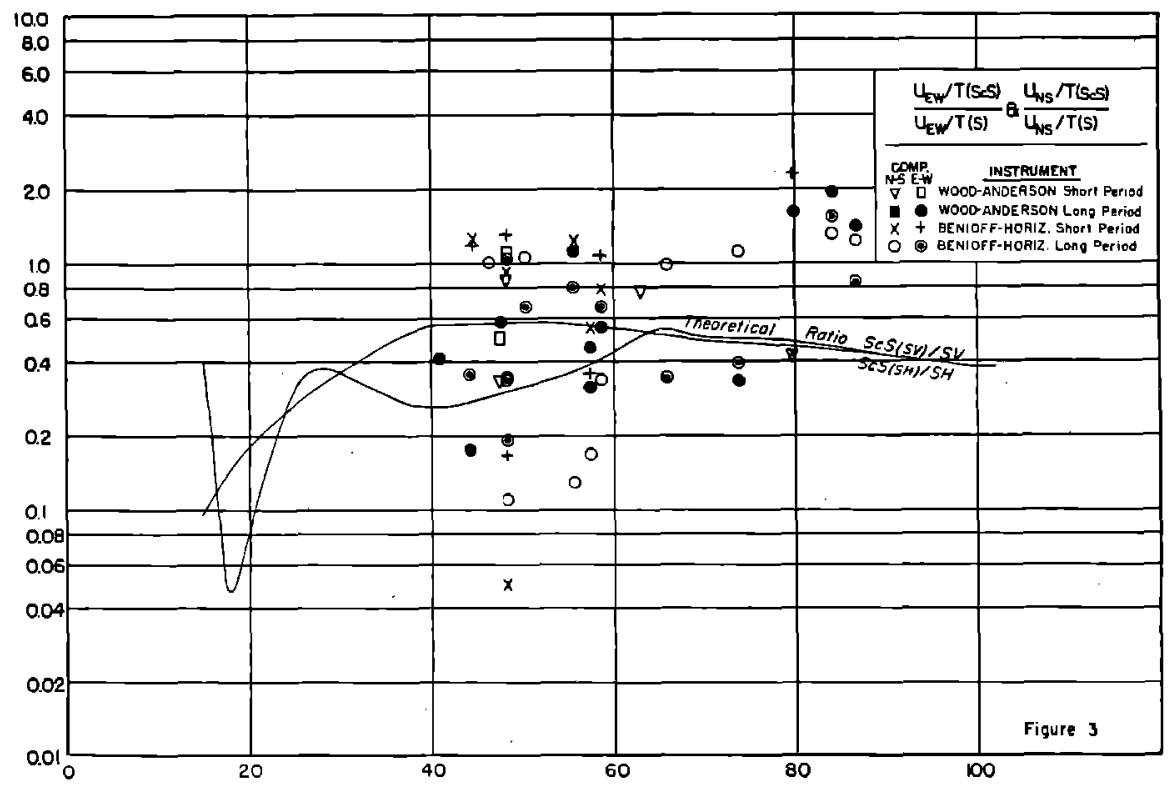

Fig. 3. Observed horizontal displacement/period ratios of ScS/S. 
The $u / T$ ratios of $\mathrm{PcP} / \mathrm{P}$ (fig. 1) show observed values of approximately ten times the theoretical values. The $w / T$ ratios of $\mathrm{PcP} / \mathrm{P}$ (fig. 2 ) are not so inconsistent, being, in general, only two to five times greater than the theoretical curve. The $u / T$ ratios of $\mathrm{ScS} / \mathrm{S}$ (fig. 3) are fairly consistent with the theoretical computations, as are also the $w / T$ ratios of ScS/S (not reproduced), that is, they seem to group themselves fairly within the limits of probable error.

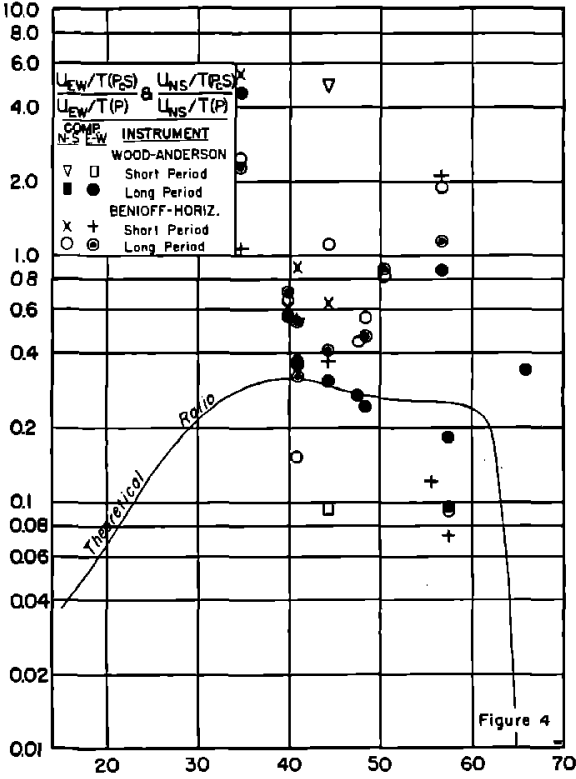

Fig. 4. Observed horizontal displacement/period ratios of $\mathrm{PeS} / \mathrm{P}$

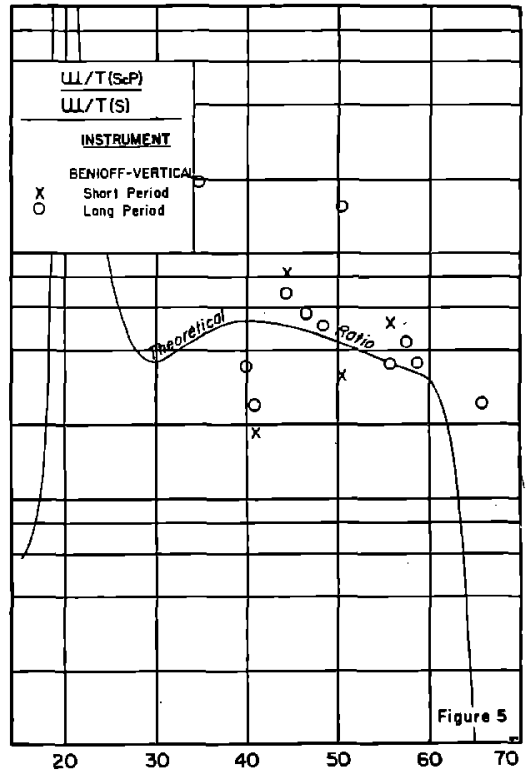

Fig. 5. Observed vertical displacement/period ratios of ScP/S

Since only shallow shocks were used, PcS and ScP theoretically arrive nearly simultaneously and cannot be separated. However, the $u_{E W}$ (or $u_{N S}$ ) $/ T$ (horizontal displacement/period ratio in the E-W and N-S directions) of $\mathrm{PcS}$ should theoretically be about three times that of $\mathrm{ScP}$ and the $w / T$ ratio of ScP should theoretically be about ten to fifteen times that of PcS, if the value of $C$ in equation (1) is the same for both an initial longitudinal and initial transverse wave at the source. Gutenberg [12] found that the value of $C^{1}$ for $S$ waves is very close to the value of $C$ for $P$ waves. Therefore, it may be assumed that the displacement in the vertical direction is mainly due to $\mathrm{ScP}$; and, more

${ }^{1}$ Gutenberg's $C$ is not the same as the $C$ used in this paper, although it is a measure of the total energy of the earthquake carried by the particular phase. If the value of $C$ given by Gutenberg is designated as $C_{1}$, and the $C$ of Dana and this paper is called $C_{2}$, it is readily shown that:

$$
\log _{10} C_{2}=(0.9 M+0.7)-C_{1}
$$

where $M=$ magnitude of earthquake. Therefore, for a given earthquake (where $M$ is a constant), if $C_{1}$ is found to be equal for different phases, $C_{2}$ must be equal for those phases. 


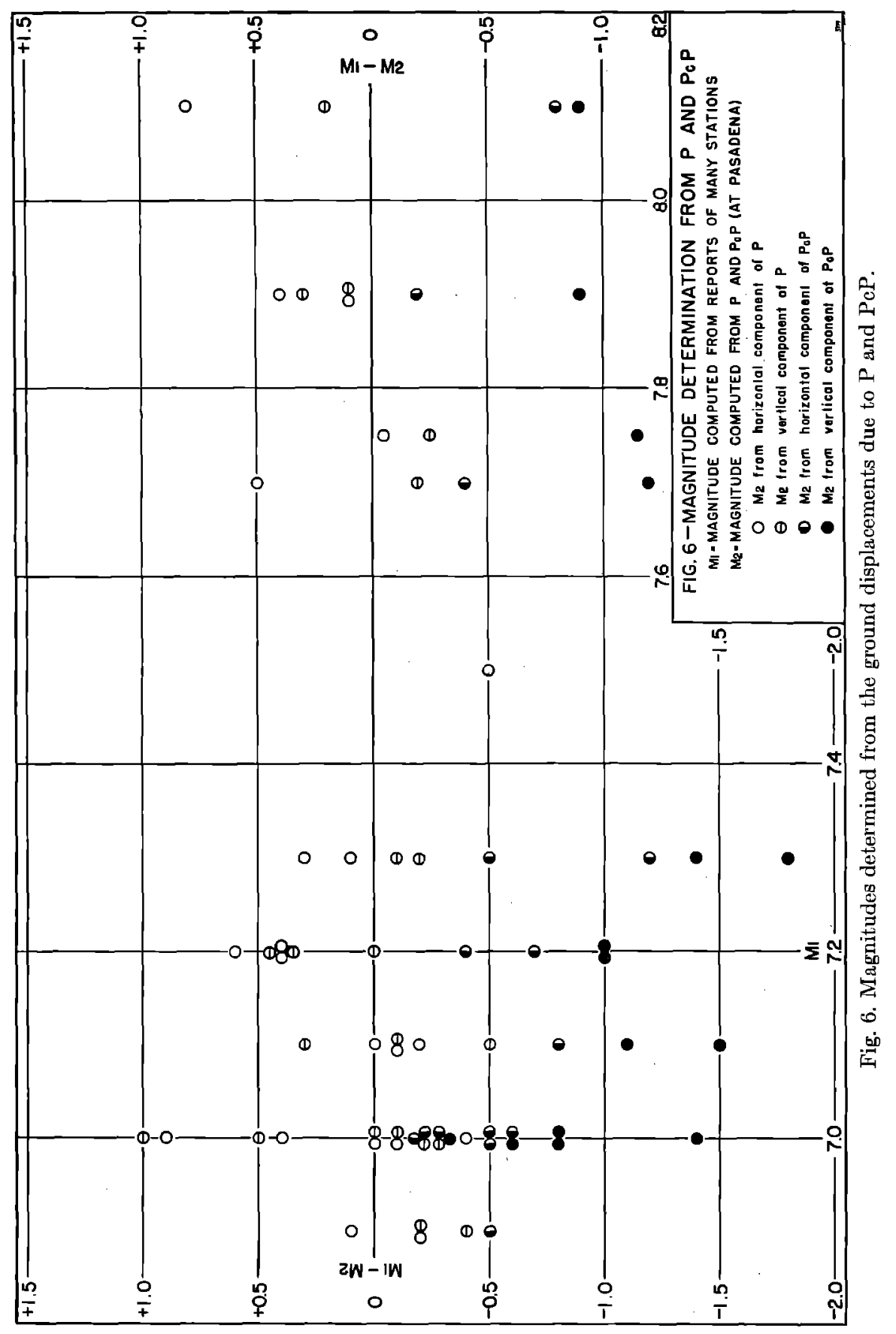


uncertainly, most of the horizontal displacement is due to PcS. Consequently, in figure 4 the $u / T$ ratio of $\mathrm{PcS} / \mathrm{P}$ was computed assuming that the horizontal displacement due to $\mathrm{ScP}$ is negligible as compared to $\mathrm{PcS}$; in figure 5 the $w / T$ ratio was computed assuming the total vertical displacement is due to $\mathrm{ScP}$. Figure 4 shows that the $u / T$ ratio of $\mathrm{PcS} / \mathrm{P}$ averages about twice its theoretical value and figure 5 indicates that the $w / T$ ratio of $\mathrm{ScP} / \mathrm{S}$ is fairly consistent with the theoretical curve.

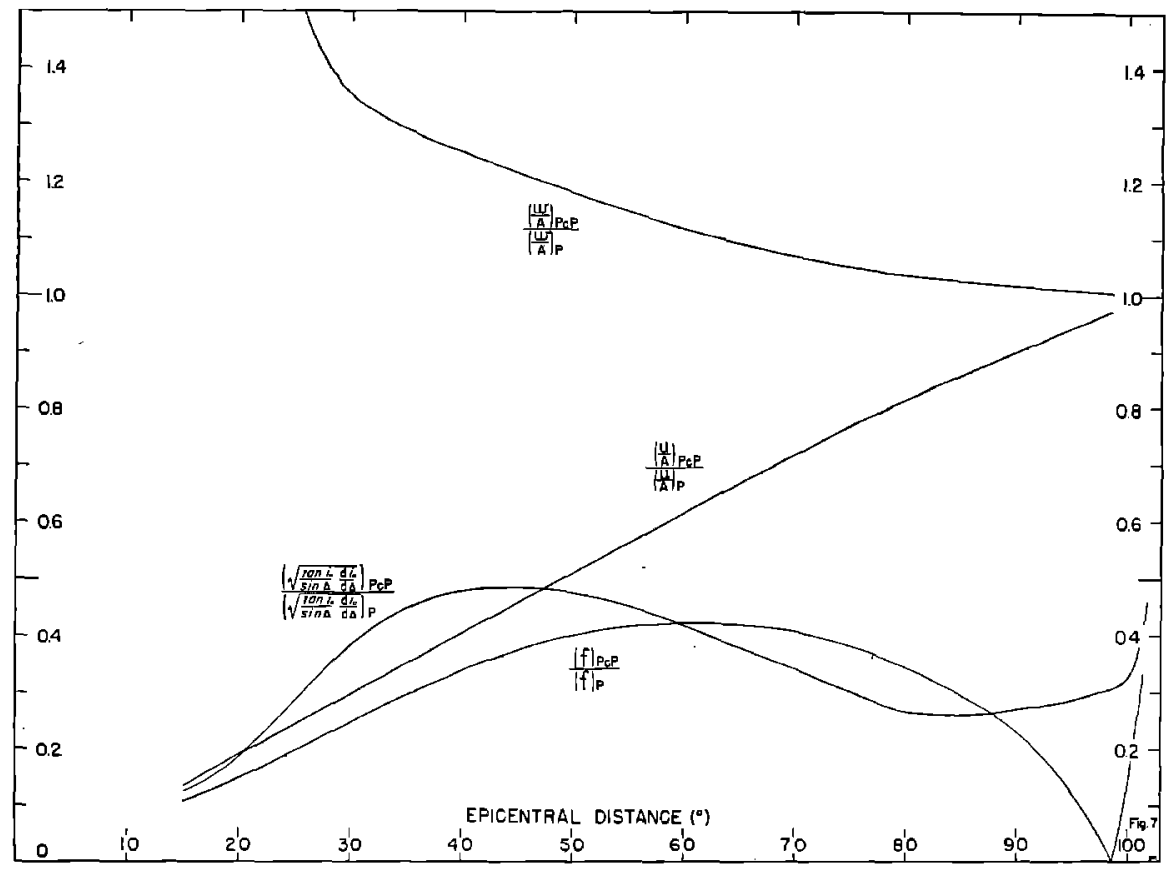

Fig. 7. Theoretical values of the various terms of

$$
u(\text { or } w)=\frac{u}{A_{e}}\left(\text { or } \frac{w}{A_{\varepsilon}}\right) C T f \sqrt{\frac{\tan i_{\mathrm{a}}}{\sin \Delta} \frac{d \overline{i_{o}}}{d \Delta}}
$$

for $\mathrm{PcP}$ divided by corresponding terms for $\mathrm{P}$ as a function of epicentral distance (see text for velocities and physical constants used).

Explanation of the discrepancies between the observed and the theoretical $u_{E W}$ (or $u_{N S}$ ) $/ T$ of $\mathrm{PcP} / \mathrm{P}$ could fall into two classifications: the theoretical displacements of $\mathrm{PcP}$ are too small, or the theoretical displacements of $\mathrm{P}$ are too great. In an effort to determine where the trouble lies, the magnitudes of the earthquakes were computed from the trace amplitudes and periods by means of a formula developed by Gutenberg [12]. This formula was extended for use with PcP (having been used previously with $\mathrm{P}$ and PP). Figure 6 shows the difference between the magnitude obtained by using data for various phases and from many seismic stations and the magnitude computed from the 
data gathered for this report using Gutenberg's formula. There is an indication that the magnitudes determined from the vertical component of the ground displacement due to $\mathrm{PcP}$ are slightly too great and that those determined from the horizontal components of $\mathrm{PcP}$ are approximately 1.0 magnitude too large. This implies that $\mathrm{PcP}$, and not $\mathrm{P}$, varies from expectations.

The foregoing results invite a closer scrutiny of the factors involved in the theoretical determination of the displacements of PcP. Figure 7 shows the percentage change of the displacement/period ratio due to the terms of formulas (1) and (2) for $\mathrm{PcP} / \mathrm{P}$ at various epicentral distances. Since the absorption term was not calculated into the theoretical curves presented in figures 1 to 5 , it has not been included on this graph, although it varies from 0.7 at $0^{\circ}$ to 1.0 at $103^{\circ}$, as previously mentioned. The effect of absorption, if included in figures 1 to 5 , would be to enlarge further the difference between the observations and theory. None of the terms plotted can exceed unity when $u / T$ is considered. Figure 7 reveals that, even if any one term were assumed to be this maximum between, say, $50^{\circ}$ and $60^{\circ}$, a supposition contradicted by many other theoretical and observed considerations, an increase in the theoretical $u / T$ of only two and one-half times would be accomplished.

Additional study was made of the effects on $f$ of variations of the assumed values of the physical constants on either side of the core boundary. The velocity of longitudinal waves and the velocity of shear waves in the mantle adjacent to the core boundary of $13.7 \mathrm{~km} / \mathrm{sec}$. and $7.25 \mathrm{~km} / \mathrm{sec}$., respectively, is established within close limits of error; within the core possible error is greater (see Macelwane [17], Gutenberg and Richter [13]). If, contrary to the assumption that the core has negligible rigidity, shear waves were transmitted into the core, the calculated amount of reflected energy would decrease, causing still further reduction in the theoretical displacement values, which are already too small. The ratio of the densities on either side of the core boundary is more doubtful than the corresponding ratios of the velocities. The values used by Dana $\left(\rho_{2}=10.1 \mathrm{gm} / \mathrm{cm}^{3}, \rho_{1}=5.4 \mathrm{gm} / \mathrm{cm} .{ }^{3}\right)$ were taken from Bullen [2 and 3], who, in a revised work, assigns the value $\rho_{2}=9.69$ $\mathrm{gm} / \mathrm{cm}^{3}$ and $\rho_{1}=5.56 \mathrm{gm} / \mathrm{cm} .^{3}$. In recalculating $f$, the values in the mantle adjacent to the core boundary were left unchanged, but the velocity of $\mathrm{P}$ in the outer part of the core and $\rho_{2} / \rho_{1}$ were varied. Limits of $9.0 \mathrm{~km} / \mathrm{sec}$. and $7.0 \mathrm{~km} / \mathrm{sec}$. were placed on the former; values beyond these are considered highly improbable. For $\rho_{2} / \rho_{1}$ extreme limits of 2.0 and 1.0 were set; anything beyond these would involve density distributions in the core that are considered impossible. The value of $f$ is always positive, and it has been graphed in figure 8 above and below the zero line to avoid confusion. The points where the curves cross the axis are changes in phase (compression to dilatation) of the reflected wave at the reflecting surface. The maximum increase in $u$ (or $w) / T$ obtainable in this way (see fig. 8) would be only about 16 per cent. 
The spread of the reflected seismic energy due to the convexity of the core's surface, which makes the reflecting surface act as a convex mirror instead of as a plane mirror, is theoretically included in the $d i_{o} / d \Delta$ term of equation (1) (see [8]).

Variations of the angle of incidence at the core within the limits of uncertainty would not affect seriously the value of $f$ (see fig. 8).

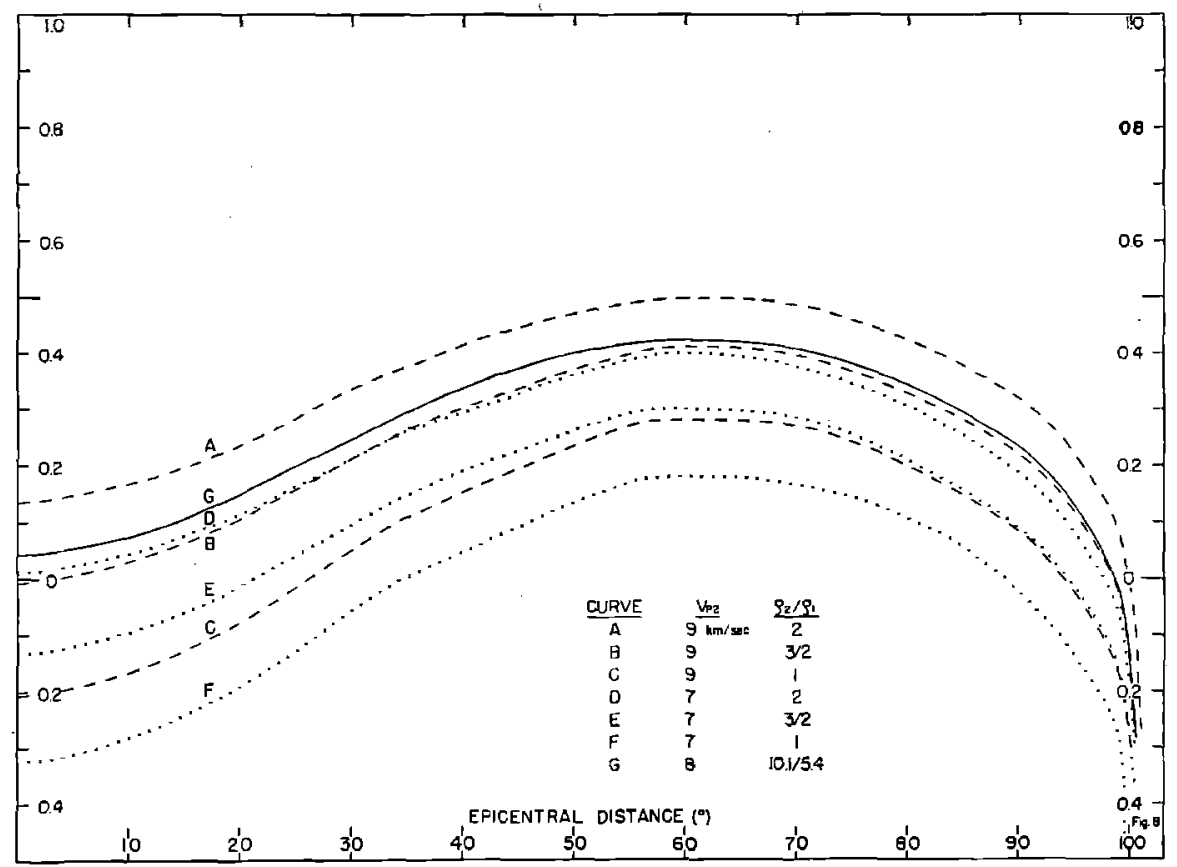

Fig. 8. Theoretical values of $f$ for an incident and reflected longitudinal wave at the core boundary as a function of epicentral distance $\left(V_{p 2}=\right.$ longitudinal wave velocity in outer part of the core, $\rho_{2}=$ density in the outer part of the core, $p_{1}=$ density in the inner part of the mantle; all values adjacent to the core boundary).

One. of the assumptions made in the theory is that there is no first-order discontinuity between the bottom of the crust and the core boundary which would seriously change the angle of incidence of $\mathrm{PcP}$ at the core.

Certain conditions near the surface of the earth require discussion. The possibility exists that the energy might not leave the focus of the earthquake equally in all directions. To increase the theoretical displacement ratios of $\mathrm{PcP} / \mathrm{P}$, the assumption would have to be made that, in general, more energy be propagated downward than horizontally at the source. If this were true, at large epicentral distances where the angles of incidence of $\mathrm{P}$ and $\mathrm{PcP}$ are approximately the same there would be a large decrease in the observed displacement ratios, a fact not borne out by the graphs. One might argue that 
$\mathrm{PcP}$, in some unexplained manner, leaves the focus in a different azimuthal direction from P. Calculations of variations between the true azimuths from Pasadena to the epicenters and the azimuths calculated from the $\mathrm{E}-\mathrm{W}$ and $\mathrm{N}-\mathrm{S}$ displacements shown by the long-period Benioff instruments indicate the same direction of the arriving $\mathrm{PcP}$ and $\mathrm{P}$ waves.

The values of the wave velocities of the longitudinal waves $\left(V_{o}\right)$ and transverse waves and the dependent angles of incidence $\left(i_{o}\right)$ at the surface of the earth are involved in the theoretical computations. In Dana's calculations, $V_{o}$

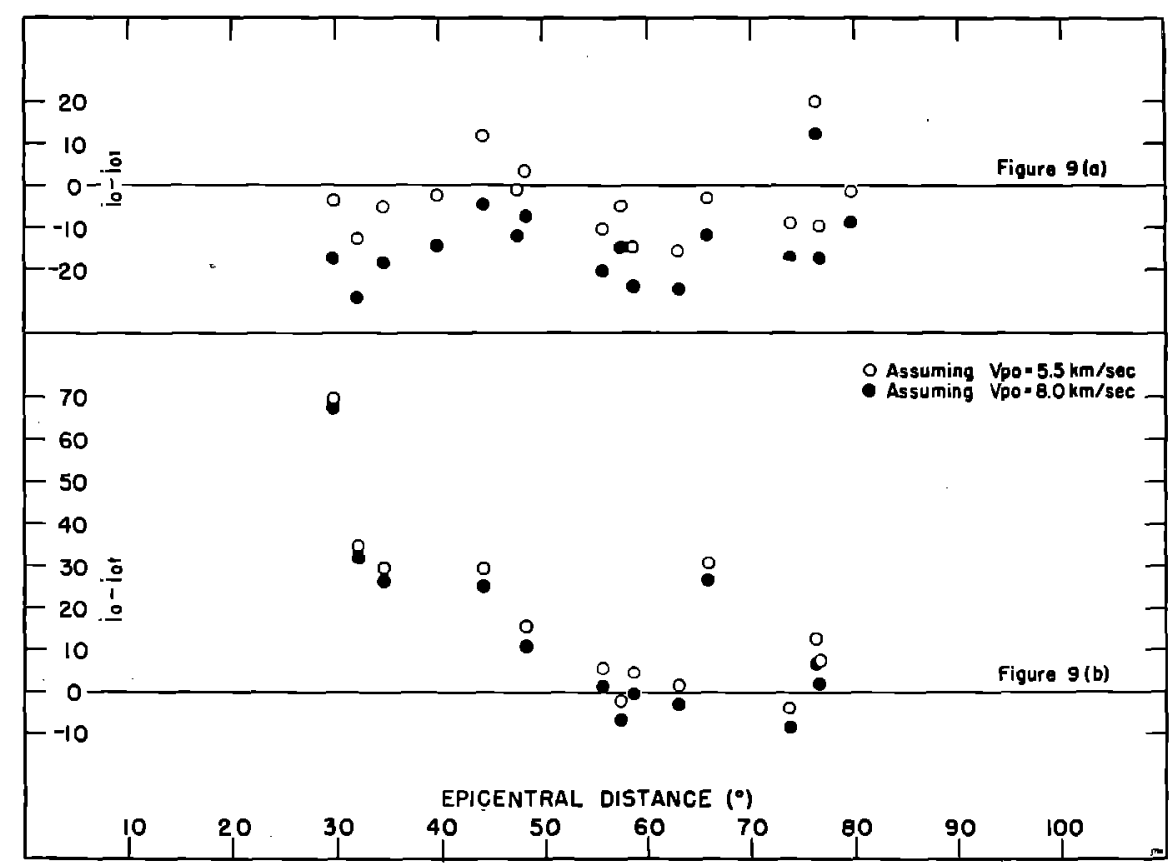

Fig. 9. a. Observed angles of incidence $i_{o}$ minus theoretical angles of incidence $i_{o t}$ for $\mathrm{P}$ at various epicentral distances. $b . i_{o}-i_{a t}$ for $\mathrm{PcP}$ at various epicentral distances.

was assigned a value of $5.5 \mathrm{~km} / \mathrm{sec}$, approximately the value determined for the "granitic" layer under Pasadena [9 and 10]. However, the crustal layers may be too thin, with respect to the wave lengths of $\mathrm{P}$ and $\mathrm{PcP}$ at large epicentral distances, to affect the angles of incidence. If the period of a seismic wave is, for example, 3 seconds, the wave length in a medium with a velocity of $5.5 \mathrm{~km} / \mathrm{sec}$. is $161 / 2 \mathrm{~km}$., which is comparable with the $18-\mathrm{km}$. thickness of the "granitic" layer near Pasadena. Below the "granitic" layer are two "basaltic" layers, totaling some $19 \mathrm{~km}$. thick near Pasadena, which have velocities for longitudinal waves of 6.0 and $6.9 \mathrm{~km} / \mathrm{sec}$. Below this is the outer boundary of the mantle, with a velocity of $8.0 \mathrm{~km} / \mathrm{sec}$. Due to the prevalence 
of periods of $\mathrm{P}$ and $\mathrm{PcP}$ of several seconds, it is doubtful how the angles of incidence of these phases correspond to the various velocities in the crust. To investigate this, angles of incidence of $\mathrm{P}$ and $\mathrm{PcP}$ were computed from the observed displacements of the long-period Benioff instruments by use of the conventional equations for the "apparent" angle of incidence $\bar{\imath}$ and the true angle $i_{o}$ and a conversion table prepared by Gutenberg [8]. These computed

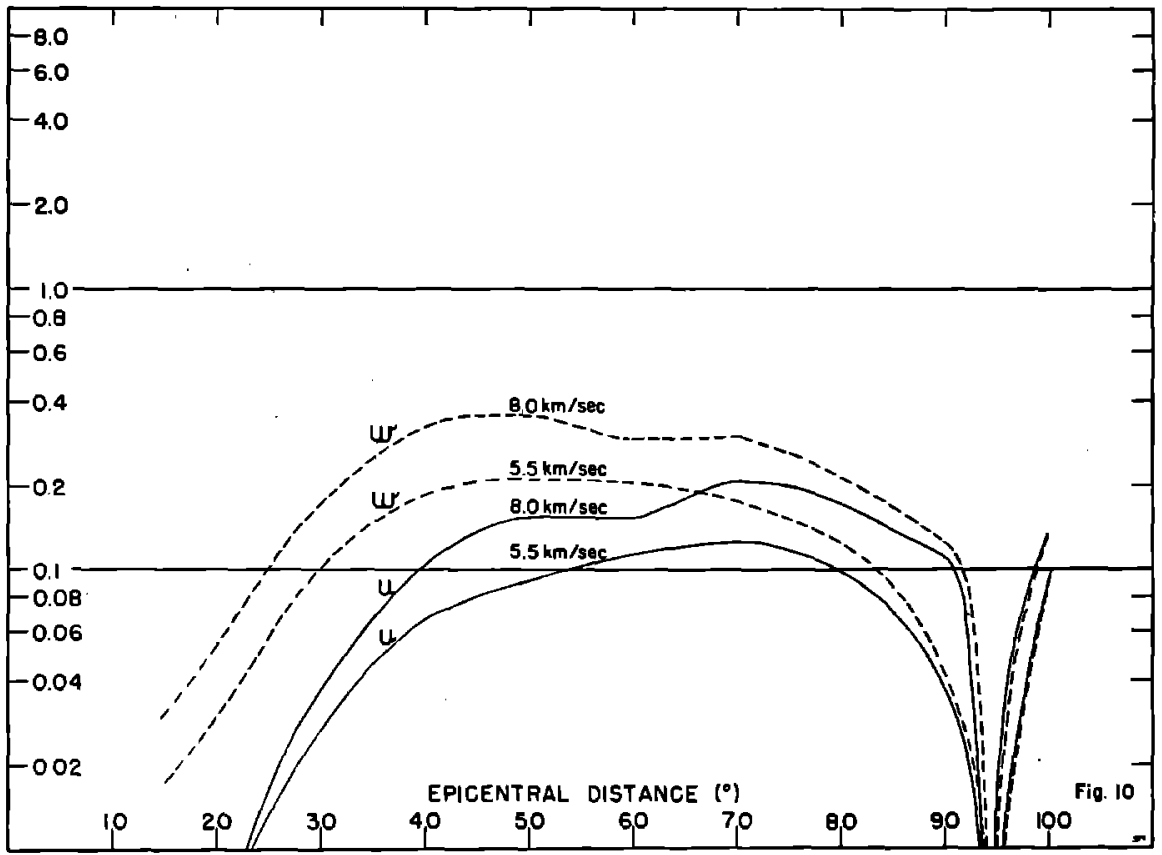

Fig. 10. Theoretical values of horizontal $(u)$ and vertical $(w)$ displacement/period ratios as a function of epicentral distance (assuming the velocity of longitudinal waves at the surface of the earth $=5.5 \mathrm{~km} / \mathrm{sec}$. and $8.0 \mathrm{~km} / \mathrm{sec}$.

values of $i_{o}$ for $V_{o}=5.5 \mathrm{~km} / \mathrm{sec}$. are compared with corresponding values of the theoretical angles of incidence at the surface of the earth $\left(i_{o t}\right)$ taken from Dana [4] (see fig. 9).

To investigate the effects of the crustal layers on the angles of incidence, $i_{o}-i_{o t}$ was computed, assuming $V_{o}=8.0 \mathrm{~km} / \mathrm{sec}$. (see fig. 9). The following formula (Gutenberg [8]) was used to obtain $i_{o t}$ for $\mathrm{P}$ :

$$
\sin i_{o t}=V_{o} / \bar{V} \text {, }
$$

where $\bar{V}=$ "apparent" velocity as computed from the travel-time curve (values taken from Dana [4]). The ray equation

$$
r \sin i / V=\text { constant }
$$


was used to determine $i_{o t}$ for PcP. Values of the angles of incidence at the core were taken from Gutenberg and Richter [13].

The plots for $\mathrm{P}$ in figure 9 show the scatter that is expected from this method of obtaining the angles of incidence, but they are grouped fairly well around the zero line. However, the plots for $\mathrm{PcP}$ show a peculiar arrangement that indicates little variation at about $65^{\circ}$ but an increasing difference with a decrease in epicentral distance. This deviation of the observed angles of incidence of $\mathrm{PcP}$ from their theoretical values is at present unexplained. The use of $V_{o}=8.0 \mathrm{~km} / \mathrm{sec}$. instead of $5.5 \mathrm{~km} / \mathrm{sec}$. makes little difference in a consideration of this variation.

Varying the velocity at the surface produces considerable change, however, in the theoretical displacement/period ratios of $\mathrm{PcP} / \mathrm{P}$ because of the $\sqrt{\frac{\tan i_{o} d i_{o}}{\sin \Delta d \Delta}}$ term. $u / T$ and $w / T$ have been computed for various epicentral distances using this larger value of $V_{o}$, and the results are given in figure 10. The graph reveals that the theoretical displacement/period ratios are increased by $11 / 2$ to 2 times when $V_{o}=8.0 \mathrm{~km} / \mathrm{sec}$. instead of $5.5 \mathrm{~km} / \mathrm{sec}$. This correction, while in the right direction for diminishing the difference between the observed and theoretical values, is far too small to explain the full variation of the horizontal displacement/period ratios of $\mathrm{PcP} / \mathrm{P}$.

\section{Conclusions}

A study of the ratios of the observed ground displacements produced by seismic waves reflected from the earth's core to those produced by direct body waves strongly indicates that the horizontal displacement/period ratios of $\mathrm{PcP} / \mathrm{P}$ are definitely larger than expectations from the currently accepted theory; the vertical displacement/period ratios of $\mathrm{PcP} / \mathrm{P}$ and the horizontal displacement/period ratios of $\mathrm{PcS} / \mathrm{P}$ are slightly greater, but not unreasonably so; and the horizontal displacement/period ratios of $\mathrm{ScS} / \mathrm{S}$ and the vertical displacement/period ratios of $\mathrm{ScS} / \mathrm{S}$ and $\mathrm{ScP} / \mathrm{S}$ are reasonably in accordance with theoretical values.

Further results indicate that the discrepancies involve the $\mathrm{PcP}$ phase and not the $\mathrm{P}$ phase. Magnitudes of the earthquakes investigated, when computed from the ground displacements produced by $\mathrm{PcP}$, are definitely greater than the sizes of the earthquakes warrant; whereas the magnitudes determined from $P$ are consistent with expectations. Another result is that at the earth's surface the angles of incidence of the PcP waves are not in accordance with their theoretical values; whereas the $\mathrm{P}$ waves are reasonably conformable.

An investigation of the theoretical formulae for the displacement due to a seismic wave reveals that no single factor can be changed sufficiently to account for the observed horizontal displacement/period ratios of $\mathrm{PeP} / \mathrm{P}$. A 
reasonable change in the physical constants of the earth's core produces only about 16 per cent change in these ratios. The assumption that the core acts as a solid leads to even greater discrepancies. An assumption that the energy is, in general, propagated from the focus in an unequal manner, such that PcP would receive more than the amount it would obtain with equal distribution, does not seem to be in accord with the observed ratios. The assumption that the angle of incidence at the Mohorovičic discontinuity should be used (since the thickness of the crustal layers is comparable with the wave length) would account for about 15 to 20 per cent of the discrepancy of the horizontal displacement/period ratios of $\mathrm{PcP} / \mathrm{P}$ and would improve the fit of the other phases. The angles of incidence of $\mathrm{PcP}$ computed from the observed data do not agree with the values computed from ray theory either on this assumption or on the assumption that the seismic waves' angles of ineidence are affected by the crustal layers; their peculiar behavior is, as yet, not definitely explained.

Assumptions made in deriving the instrumental constants and frequency response characteristics introduce errors which are considered small with respect to the variation of the displacement/period ratios from their theoretical values.

In the derivation of the formulae for the reflection coefficients at the core boundary the assumption of plane waves is a simplification which may not be justified. If a more complete analysis of the problem would lead to the result that the reflected compressional wave contains a transverse component in addition to its longitudinal motion, this would serve to explain the apparently greater angle of incidence computed from the observed amplitudes of $\mathrm{PcP}$.

\section{ACKNOWLEDGMENTS}

The author wishes to express his gratitude for the supervision, help, and inspiration of Dr. Beno Gutenberg, who contributed much to the completion of this study. The writer is also grateful for the coöperation of Dr. Hugo Benioff in overcoming some of the instrumental problems. Mr. Francis Lehner supplied helpful assistance while instrumental constants were determined. The final draft was reviewed by Professors Gutenberg, Benioff, and Richter, and their constructive criticism was appreciated.

This work was completed while the writer held a fellowship provided by the Stanolind Oil and Gas Company, whose financial assistance is gratefully acknowledged. 


\section{ReFERENCES}

[1] Blut, H. "Ein Beitrag zur Theorie der Reflexion und Brechung elastischer Wellen an Unstetigkeitsflächen," Zeit. Geophysik, 8:130-144, 305-322 (1932).

[2] Bullen, K. E. "The Variation of Density and the Ellipticities of Strata of Equal Density within the Earth," Mon. Not. Roy. Astron. Soc., Geophys. Suppl., 3:395-401 (1936).

[3] - "Note on the Density and Pressure Inside the Earth," Roy. Soc. New Zealand, Trans., 67:122-124 (1937).

[4] Dana, S. W., "Amplitudes of Seismic Waves Reflected and Refracted at the Earth's Core," unpublished thesis, Calif. Inst. of Technology, Pasadena, California (1944).

[5] "The Partition of Energy among Seismic Waves Reflected and Refracted at the Earth's Core," Bull. Seism. Soc. Am., 34:189-197 (1944).

[6] _ _The Amplitudes of Seismic Waves Reflected and Refracted at the Earth's Core," Bull. Seism. Soc. Am., 35:27-35 (1945).

[7] Geiger, L., and B. Gutenberg. "Ueber Erdbebenwellen VI," Nachr. Gesell. Wiss. Göttingen, math.-phys. Kl., pp. 623-675 (1912).

[8] Gutenberg, B. "Theorie der Erdbebenwellen," Handbuch der Geophysit, Vol. 4 (1932).

[9] _ _Travel Times of Principal P and S Phases over Small Distances in Southern California," Bull. Seism. Soc. Am., 34:13-32 (1944).

[10] - "Reflected and Minor Phases in Records of Near-by Earthquakes in Southern California," Bull. Seism. Soc. Am., 34:137-160 (1944).

[11 ] _ _ "Energy Ratio of Reflected and Refracted Seismic Waves," Bull. Seism. Soc. $A m ., 34: 85-102$ (1944).

[12] _Amplitudes of P, PP, and S and Magnitudes of Shallow Earthquakes," Bull. Seism. Soc. Am., 35:57-69 (1945).

[13] Gutenberg, B., and C. F. Richter. "On Seismic Waves" (fourth paper), Gerlands Beitr. Geophys., 54:94-136 (1939).

[14] _ _Seismicity of the Earth". (supplementary paper), Bull. Geol. Soc. Am., 56:603-668 (1945).

[15] Jeffreys, H. "The Reflexion and Refraction of Elastic Waves," Mon. Not. Roy. Astron. Soc., Geophys. Suppl., 1:321-334 (1926).

[16] Knott, C. G. "Reflexions and Refractions of Elastic Waves, with Seismological Implications," Phil. Mag., fifth series, Vol. 48 (1899), No. 290, pp. 64-97. Reprinted from Transactions of the Seismological Society of Japan (1888).

[17] Macelwane, J. B. "Evidence on the Interior of the Earth from Seismic Sources," Physics of the Earth-VII, Internal Constitution of the Earth (New York: McGrawHill, 1939), chap. 10.

[18] Richter, C. F. "An Instrumental Earthquake Magnitude Scale," Bull. Seism. Soc. Am., 25:1-32 (1935).

[19] Zoeppritz, K. "Ueber Erdbebenwellen VIIв," Nachr. Gesell. Wiss. Göttingen. math.phys. Kl. (1919), pp. 57-84.

[20] Zoeppritz, K., L. Geiger, and B. Gutenberg. "Ueber Erdbebenwellen V," Nachr. Gesell. Wiss. Göttingen, math.-phys. Kl. (1912), pp. 121-206. 